\title{
POROUS CHITSAN-GELATIN SCAFFOLDS EMBEDDED WITH PLGA NANOPARTICLES FOR BONE REPAIR.
}

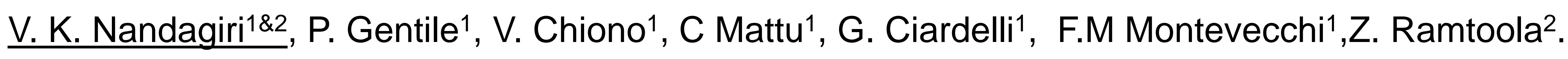

1. Politecnico di Torino, Department of Mechanics, Corso Duca degli Abruzzi 24, 10129 Turin, Italy,

2. School of Pharmacy, Royal College of Surgeons in Ireland, York House, Dublin 2, Ireland.

\section{POLITECNICO DI TORINO}

Vijay.nandagiri@polito.it

\section{Introduction}

In the domain of tissue engineering, the repair of skeletal defects is an immediate clinical need as impaired fracture healing or nonunion bone defects often result in a functional disability for which there is no effective therapy [1].Conventional tissue engineering strategies utilize combination of biodegradable porous scaffolds and bioactive molecules such as growth factors to mimic natural processes of healing [2]. However, such approaches often produce unpredictable results, probably due to the short biological half life of bioactive molecules and lack of long term stability and tissue specificity [3]. The aim of this work is to prepare chitosan-gelatin $(\mathrm{CH} / \mathrm{G})$ scaffolds embedded with PLGA nanoparticles for the purpose of localized growth factor delivery at a pre-determined rate and to improve the therapeutic efficiency of scaffolds by mimicking the endogenous release of bioactive substance(s).

\section{Materials and Methods}

Chitosan $(\mathrm{CH})$ and Type A gelatin $(\mathrm{G})$ from porcine skin were supplied from Sigma-Aldrich.

\section{$3 \%(w / v)$ CH-G (at a weight ratio $1: 2$ ) solution in $0.5 \mathrm{M}$ acetic acid, stir for $12 \mathrm{~h}, 40^{\circ} \mathrm{C}$}

Add Genipin 2.5\% w/w w.r. gelatin/chitosan amount.

\section{The mixture was kept at $50^{\circ} \mathrm{C}$ under stirring unti} a gel started to form.

\section{Spread the gel on Petri dishes and freeze-dried for $24 \mathrm{~h}$ to obtain porous matrices. Excess genipin was removed by repeated alternative washings with $0.1 \mathrm{~N} \mathrm{NaOH}$ and water.}

Figure 1. Fabrication of porous $\mathrm{CH}-\mathrm{G}$ scaffolds. (Ref. 4)

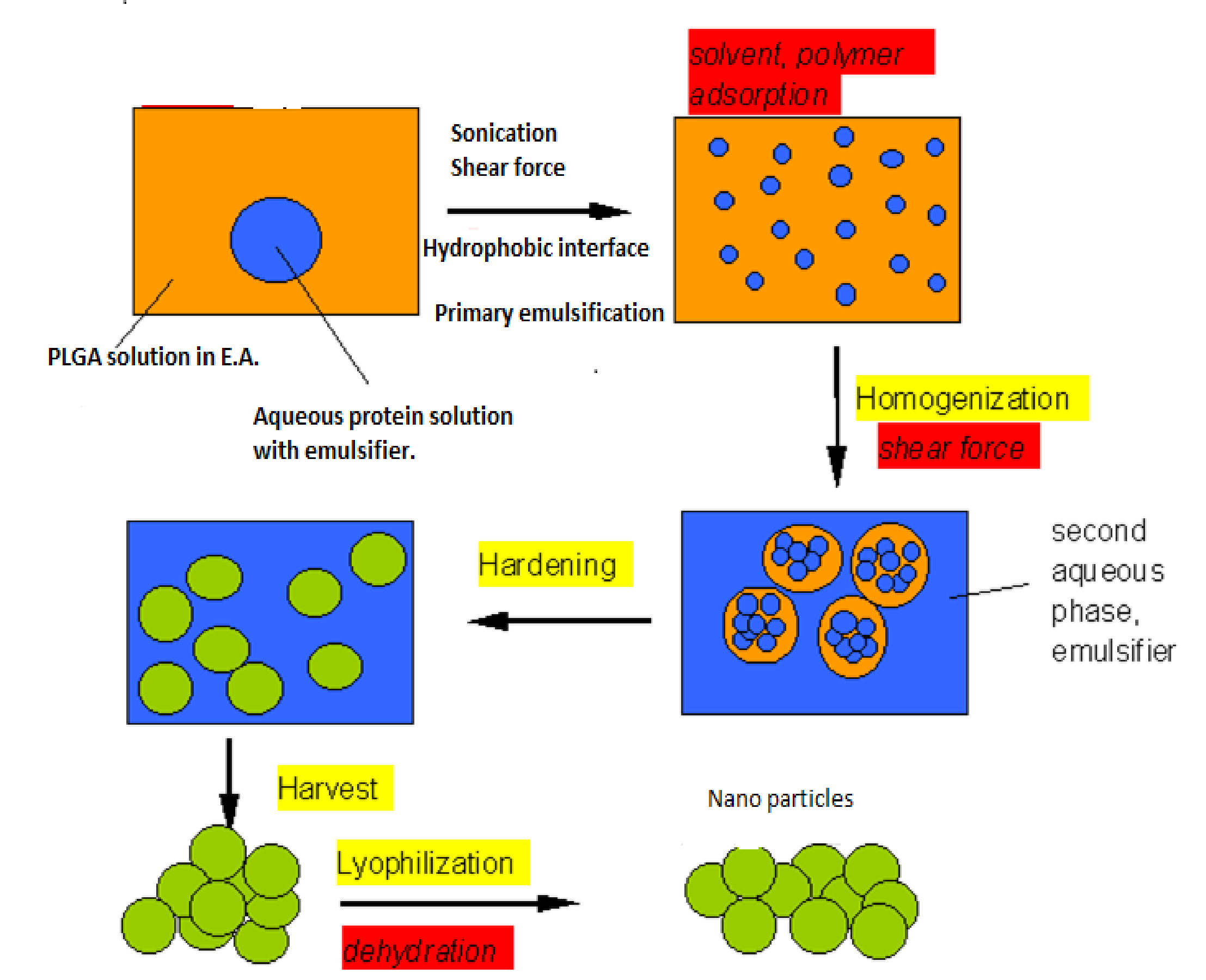

Figure 2. Schematic representation of formation of PLGA nanoparticles (Ref. 5)

Nanoparticles-embedded scaffolds were constructed by dispersing various amounts of PLGA nanoparticles (PLGA $\mathrm{NP}$ ) into $1 \mathrm{ml}$ of $\mathrm{CH} / \mathrm{G}$ blend solution before the pre-frozen and freezedrying steps, which were described above. Scaffolds were characterised for their stability (swelling and dissolution tests), morphology (scanning electron microscopy, SEM).

\section{Conclusions}

Scaffolds incorporated with PLGA nanoparticles displayed lower swelling than CH/G scaffolds without nanoparticles. Incorporation of the hydrophobic PLGA nanoparticles in the relatively hydrophilic $\mathrm{CH} / \mathrm{G}$ scaffold modulated the porous structure and tensile strength of the scaffold. Studies are in progress to evaluate the release kinetics of particles embedded into $\mathrm{CH} / \mathrm{G}$ scoffolds. GP crosslinked $\mathrm{CH} / \mathrm{G}$ blends embedded with PLGA nanoparticles containing suitable growth factor can be used in the form of porous scaffolds, to enhance bone regeneration.

\section{References}

1] Salgado A.J. et al., Macromol. Biosci., 4: 743-765, 2004 [2] Borenstein J.T. et al., Tissue Eng., 13:1837-1844, 2007. [3] Kobsa S. et al., Pediatr Res., 63: 513-519,2008.

[4] Chiono V. et al., J Mater Sci Mater Med., 19:889-898,2008.

[5] Panyam J. et al. J. Control. Release, 92: 173-187, 2003.

\section{Results and discussion}

The use of $\mathrm{CH} / \mathrm{G}$ blends as scaffolding materials may affect cell adhesion, scaffold bioactivity, tissue remodelling process and the quality of the regenerated tissue. Genipin-crosslinking stabilized the chitosan-gelatin blends in water solution and pre-freezing at $-20^{\circ} \mathrm{C}$ warranted the uniform gel formation. Freezing resulted in the formation of ice crystals inside polymer solution which act as porogens during freeze drying process that resulted in a porous (160-200 microns) 3D polymer scaffold (Fig.3). PLGA nanoparticles formed ere spherical in shape and displayed a smooth surface with an average size below $200 \mathrm{~nm}$ (Fig.4). PLGA nanoparticles were uniformly distributed and located in the walls or void spaces of the $\mathrm{CH} / \mathrm{G}$ scaffold (irrespective to the amount of nanoparticles used) as witnessed in SEM image (Fig.5).

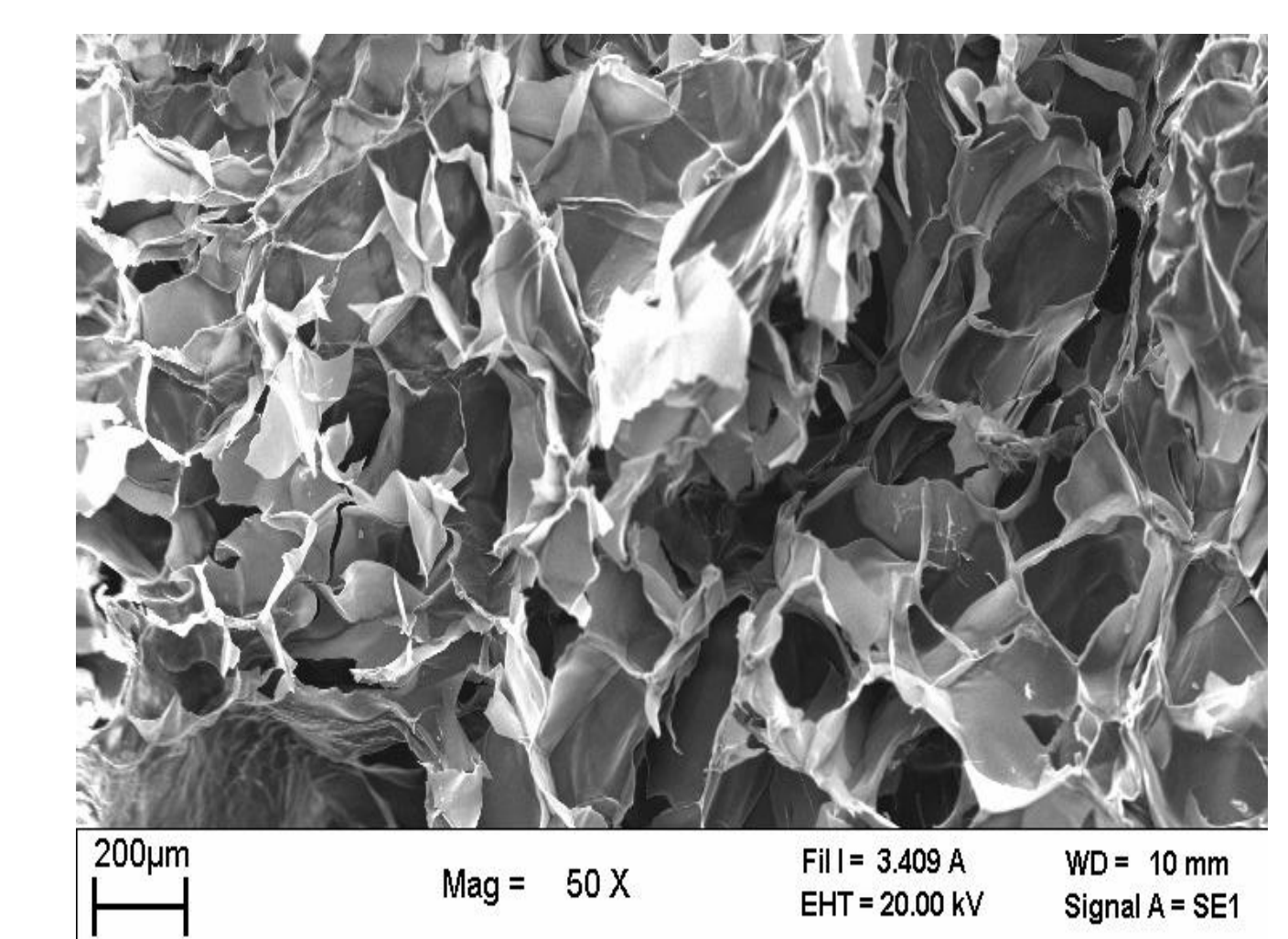

Figure 3. Porous $\mathrm{CH}-\mathrm{G}$ scaffolds

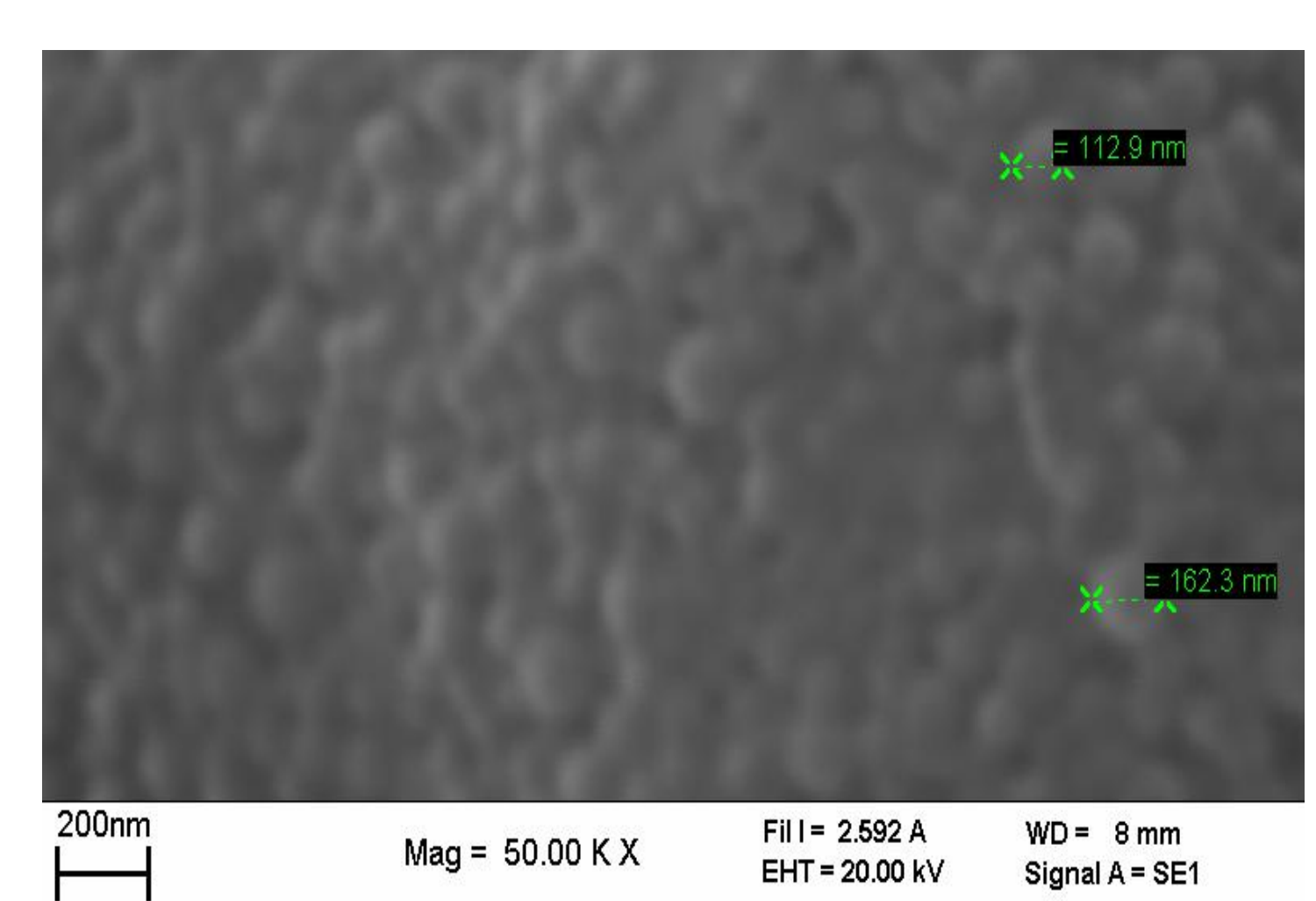

Figure 4. PLGA nanoparticles.

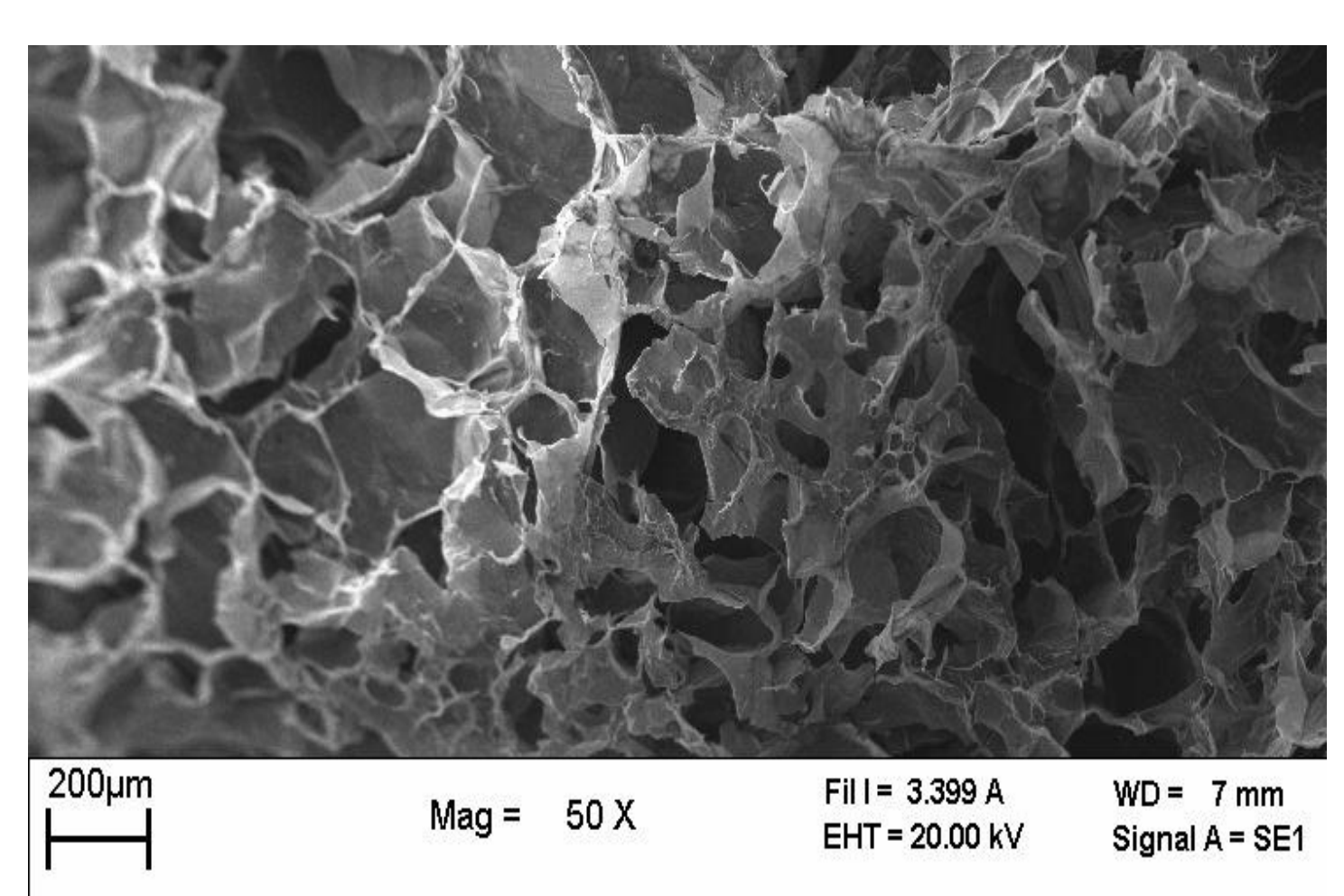

Figure 5. Porous $\mathrm{CH}-\mathrm{G}$ scaffolds embedded with PLGA nanoparticles.
Scaffolds with PLGA nanoparticles displayed heterogeneous porous structure (Fig.5) which could be attributed to the fusion of two or three adjacent pores by the rupture of common pore walls. This might be due to the steric effect of the embedded nanoparticles or to the strong water repelling force exerted by the hydrophobic nanoparticles. Furthermore, scaffolds containing PLGA nanoparticles displayed lower \% swelling and higher mechanical properties than the ones without particles (Fig.6\&7). Weight loss in water due to $\mathrm{CH} / \mathrm{G}$ release ranged between 29 to $49 \%$ for scaffolds after 10 days immersion in Phosphate buffered saline(PBS) (Tab. 1).

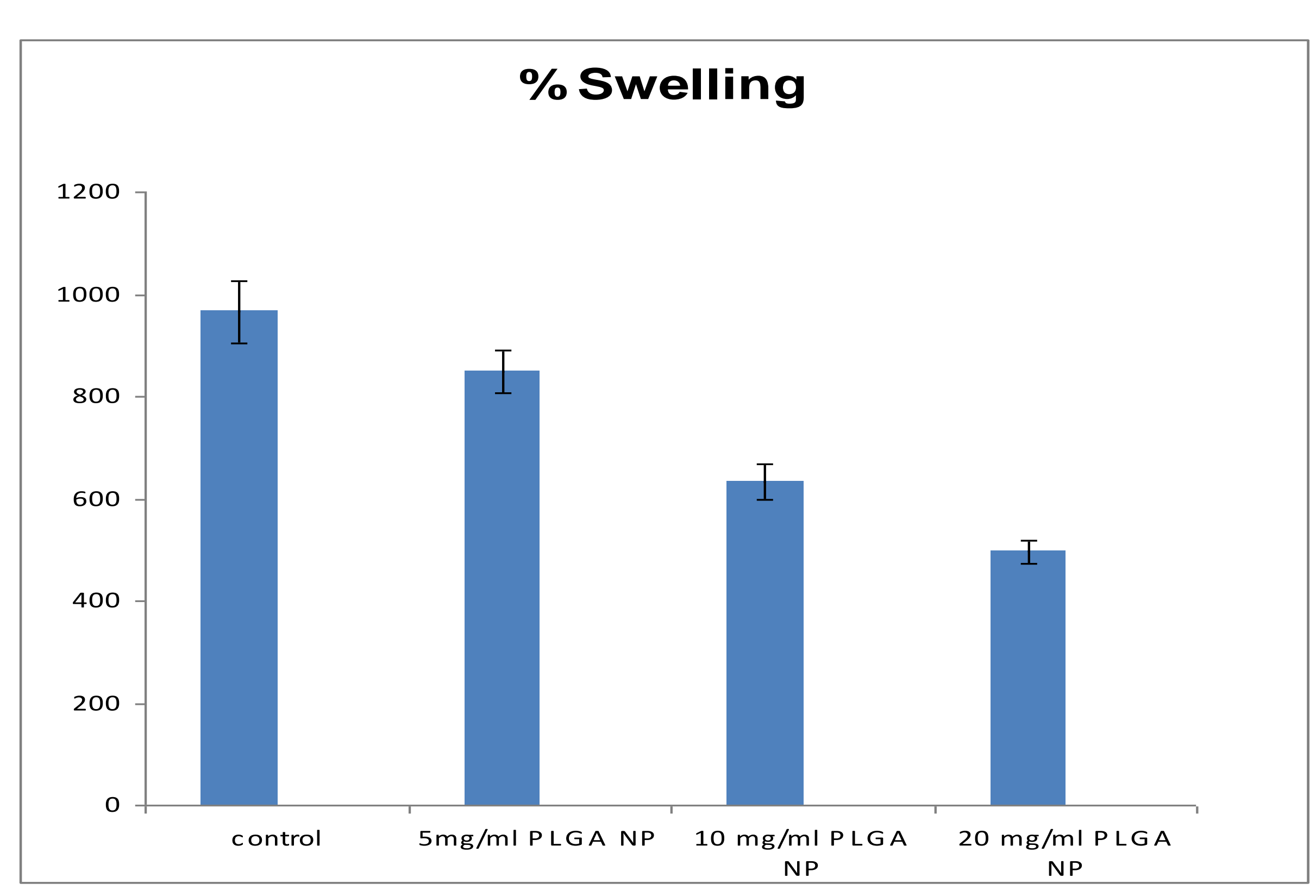

Figure 6. \%Swelling of scaffolds in PBS. Reported values are the averaqes and bars indicate the S.D. $(n=3)$ $\mathrm{pH}$ changes in incubation medium

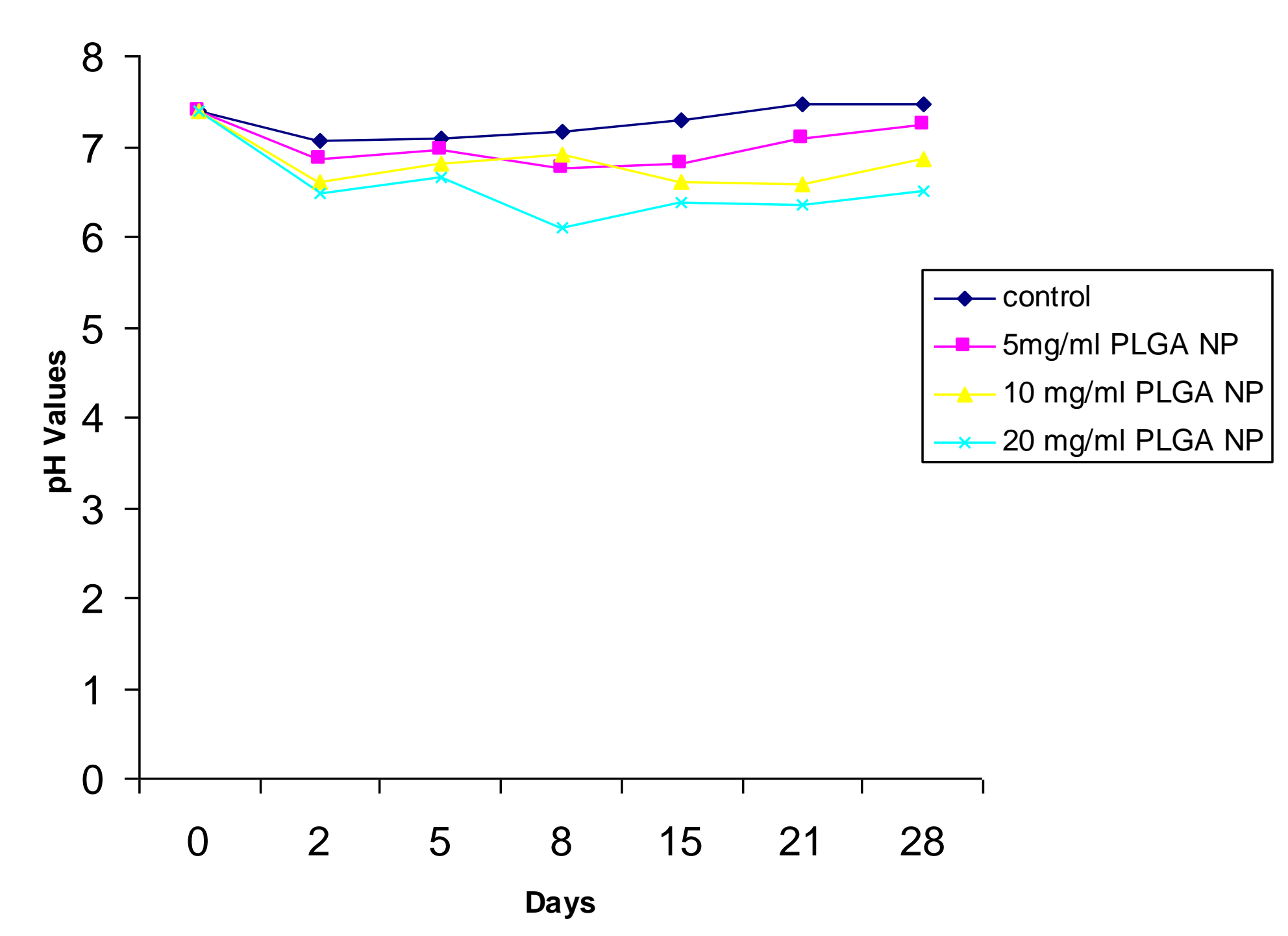

Figure 8. Supernatant $\mathrm{pH}$ changes during the dissolution of scaffolds as a function of time at $37^{\circ} \mathrm{C}$. Reported values are the averages $(n=3)$
Compressive Young's Modulus (MPa)

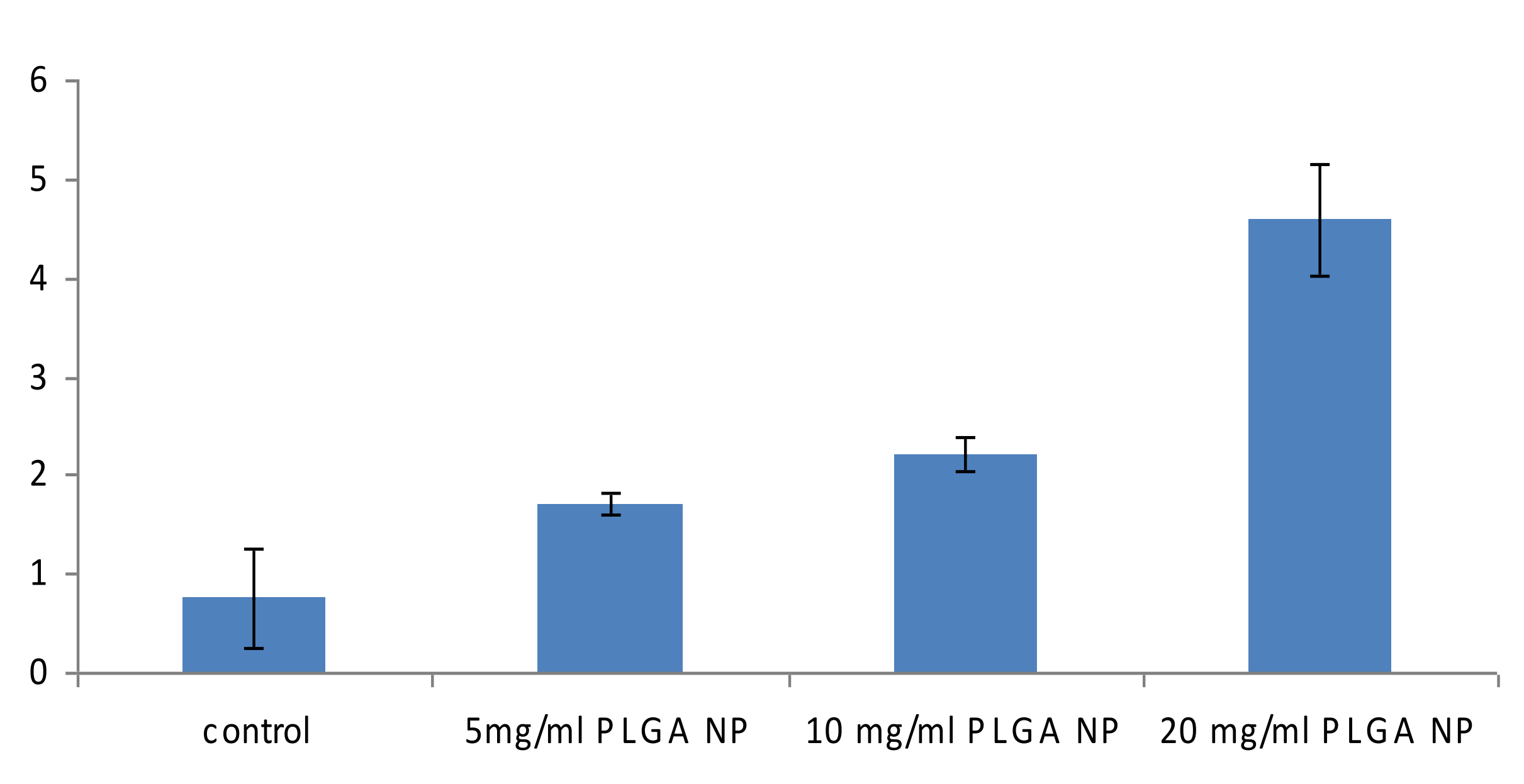

Figure 7. Compressive Young's modulus for Scaffolds. Reported values are the averages and bars indicate the S.D. $(n=3)$

\begin{tabular}{|c|c|c|c|}
\hline Group & $\begin{array}{c}\text { Initial Wt. mg } \\
\text { (mean } \pm \text { S.D.) }\end{array}$ & $\begin{array}{c}\text { Final wt. mg } \\
\text { (mean } \pm \text { S.D.) }\end{array}$ & $\begin{array}{c}\% \text { wt } \\
\text { loss }\end{array}$ \\
\hline CH-G scaffolds & $250.5 \pm 12.1$ & $127.3 \pm 13.8$ & $\begin{array}{c}49.16 \\
\pm 0.63\end{array}$ \\
\hline $\begin{array}{c}\text { CH-G with 5 mg/ml } \\
\text { PLGA NP }\end{array}$ & $258.4 \pm 20.6$ & $163.7 \pm 31.8$ & $\begin{array}{c}36.6 \\
\pm 6.43\end{array}$ \\
\hline $\begin{array}{c}\text { CH-G with 10 } \\
\text { mg/ml PLGA NP }\end{array}$ & $235.9 \pm 16.24$ & $126.6 \pm 28.6$ & $\begin{array}{c}46.63 \\
\pm 18.43\end{array}$ \\
\hline $\begin{array}{c}\text { CH-G with 20 } \\
\text { mg/ml PLGA NP }\end{array}$ & $240.1 \pm 9.1$ & $169.2 \pm 11.1$ & 29.50 \\
\pm 7.10 \\
\hline
\end{tabular}

PBS. which could be attributed to the degradation of chitosan. In case of control samples the maximum acidic condition whe $\mathrm{pH}$ raised closure to initial $\mathrm{pH}$. On the other hand, samples containing PLGA particles displayed more acidic conditions probably due to the degradation of PLGA particles. (Fig. 8) 